\title{
The GPR as a complementary tool in the Management of Contaminated Sites.
}

\author{
Coelho, F. P. ${ }^{* 1}$ and Guimarães, S.N.P. ${ }^{2}$
}

${ }^{1}$ SENAI Chemical Technology and Environment Institute

2Department of Geophysics, National Observatory - ON/MCTI

Copyright 2021, SBGf - Sociedade Brasileira de Geofísica.

This paper was prepared for presentation during the $17^{\text {th }}$ International Congress of the Brazilian Geophysical Society held in Rio de Janeiro, Brazil, $16-19$ August 2021

Contents of this paper were reviewed by the Technical Committee of the $17^{\text {th }}$ International Congress of the Brazilian Geophysical Society and do not necessarily represent any position of the SBGf, its officers or members. Electronic reproduction or storage of any part of this paper for commercial purposes without the written consent of the Brazilian Geophysical Society is prohibited.

\begin{abstract}
In the last decades, a large number of contaminated site have been identified worldwide. Mainly in sites were industrial process has occurred in an unrestrained manner and without adequate environmental controls. This growing number also generates the need for more efficient and objective evaluate mostly in deactivated industrial sites. In Brazil, the CONAMA 420/09 Resolution, recommends the stages of the management of contaminated sites. Since its evaluation until risks identification and in order to complement denote different methodology and tools that help in the identification and delimitation of contaminants. As an auxiliary tool in management of contaminated sites, the GPR (Ground Penetrating Radar) method meets the guidelines in Brazilian standard number 15935 of 2011 . The objective of this work is to present the GPR as an adjunct and guiding in the management of a deactivated industrial site located in the Rio de Janeiro state (Brazil).
\end{abstract}

\section{Results and Conclusions}

Electromagnetic anomalies were indicated by the contrast of the amplitude map of the GPR signal and divided the study area into two distinct locations: A1 and A2. In the maps generated from the GPR signal in depth, it was possible to observe the range of the zone of alteration of the magnetic wave signal, indicating possible surface and subsurface contamination, where the contours of the anomalous sites are delimited from the meeting of these different amplitudes. Areas that have strong signal attenuation indicate points where contaminants are present.

In the $A 1$ site, the results to $1.80 \mathrm{~m}$ of depth indicate three discontinuous anomalies, covering approximately $30 \mathrm{~m}^{2}, 36 \mathrm{~m}^{2}$ and $45 \mathrm{~m}^{2}$. In the $A 2$ site, two anomalous zones identified in both $1.60 \mathrm{~m}$ and $1.40 \mathrm{~m}$ depth maps have an inverse character in their spatial arrangement. The largest anomaly observed has an area of $36 \mathrm{~m}^{2}$ and the smallest $16 \mathrm{~m}^{2}$. Another important detail was the verification that the edges of these identified anomalies are interrupted implying that their dimension may be greater than the one found. In conclusion, the results point that the anomalous sites, in particular of the shallow levels of $1.40,1.60$ and $1.80 \mathrm{~m}$, maybe correlated with the potential sources existing in the unsaturated zone, and at deepest levels of 3.10 and $3.90 \mathrm{~m}$, the anomaly may represent the possible existence of groundwater contamination (plumes). 